\title{
Assessment of Factors Influencing the Implementation of Biosecurity Measures on Pig Farms in the Western Highlands of Cameroon (Central Africa)
}

\author{
Marc K. Kouam $\mathbb{D D}^{1,2}$ and Junior O. Moussala ${ }^{1}$ \\ ${ }^{1}$ Department of Animal Production, Faculty of Agronomy and Agricultural Sciences, PO BOX 188, Dschang, Cameroon \\ ${ }^{2}$ Center for Research on Filariasis and Other Tropical Diseases (CRFilMT), P.O. BOX 5797, Yaoundé, Cameroon \\ Correspondence should be addressed to Marc K. Kouam; mkouam2003@yahoo.fr
}

Received 21 January 2018; Revised 8 April 2018; Accepted 23 April 2018; Published 27 May 2018

Academic Editor: Maria Laura Bacci

Copyright (c) 2018 Marc K. Kouam and Junior O. Moussala. This is an open access article distributed under the Creative Commons Attribution License, which permits unrestricted use, distribution, and reproduction in any medium, provided the original work is properly cited.

\begin{abstract}
Biosecurity plays an irreplaceable role in preventing diseases and increasing productivity on farm. The main objective of this study was to characterize pig farming and investigate factors influencing biosecurity on pig farms in the western highlands of Cameroon. Data were collected from May to July 2017 using a questionnaire and observations. A technical scoring system was developed from the biosecurity measures. The results revealed that most farmers are males $(76.29 \%)$, on average $47.82 \pm 10.34$ years old, with secondary school level (53.61\%). The most common husbandry system is extensive (73.22\%). Over a total score of 93 , measures with higher scores (>80) included "employees do not rear pigs at home," "animals of different age not in the same room," "unsold animals from market quarantined prior to reintroduction into the herd," "production materials not exchanged among farms," "piggeries clean every day," "disinfectants used," "pigs vaccinated," and "vaccination calendar respected." Those with the lowest score $(<6)$ were "sanitary lock present," "use of herd specific clean coveralls and boots on farm," and "entry restriction sign post present." The biosecurity level was associated with production system, with the score 6.57 and 3.66 points lower for extensive and semi-intensive farms, respectively, than for intensive system. Farmer's age, gender, education level, and herd size did not affect the level of biosecurity. The results can be used to improve the general biosecurity status in pig herds in the country which in turn will lead, as observed elsewhere, to improved technical performance and economic gain.
\end{abstract}

\section{Introduction}

Cameroon's population is fast growing, as documented in a previous report [1] indicating a shift of a population from 12.1 million inhabitants in 1990 to 22.8 million inhabitants in 2014. With this growing population in the country, the demand for meat is very high. For instance, in 2009, pig farming in Cameroon provided annually only 30,000 tons of meat while the prevision was estimated at 42,000 tons for that year [2]. That year, pork consumption was estimated at $1.8 \mathrm{~kg}$ per inhabitant per year $(\mathrm{kg} / \mathrm{inh} /$ year $)$ and projected to be $2.0 \mathrm{~kg} / \mathrm{inh} /$ year in 2015 and $2.5 \mathrm{~kg} / \mathrm{inh} /$ year in 2025 [2]. Of the 265,816 tons of meat produced in 2013 , pork contribution was 35180 tons only [3]. Among the constraints limiting pig productivity, diseases have the lion's share $[2,4]$. Some of the diseases reported to occur include African swine fever (ASF), classical swine fever, Aujeszky's disease, enteritis, transmissible gastroenteritis, porcine encephalomyelitis, erysipelas, dysentery, pasteurellosis, tuberculosis, salmonellosis, and parasitic diseases $[2,5]$. For example, because of ASF, pig productivity dropped from 41,043 to 35,180 tons of meat in 2012 and 2013, respectively [3].

Different means have been developed to control these diseases in pigs and other food animals including biosecurity, vaccination, surveillance, and culling of the animals. Biosecurity, defined as a set of management practices or measures to prevent introduction and spread of pathogens within and between farms [6,7], has been reported to be the cheapest way to control diseases in flocks or herds. However, many factors have been reported to affect the adoption and 


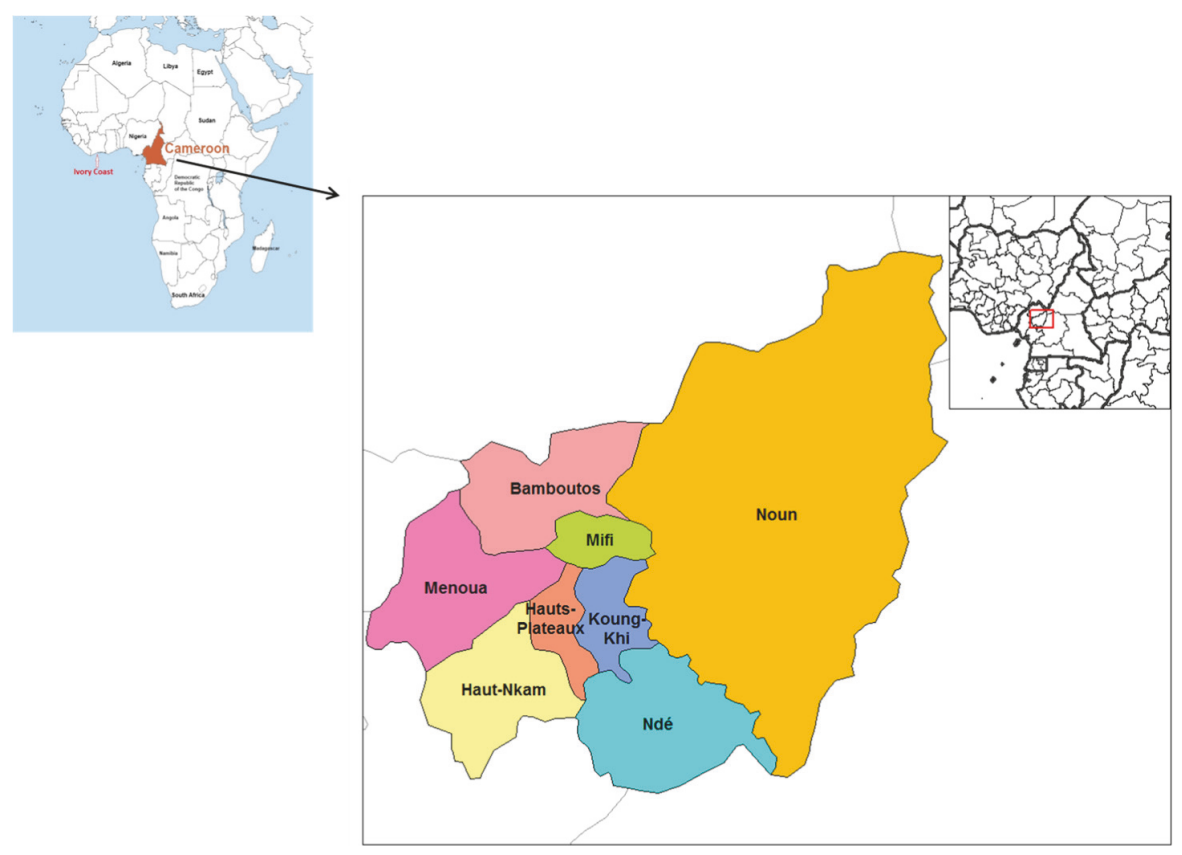

Figure 1: Map of the West Region of Cameroon showing Menoua Division.

correct implementation of biosecurity on farm. Ajewole and Akinwumi [8] reported that the level of education, farm size, and training in animal production all have significant positive influence on the poultry farms' biosecurity control score while age, number of household labor, and distance from the nearest poultry farm show significant negative influence on the farms' biosecurity control score. Similarly, Can and Altuğ [9] found that herd size and producers' education level were positively correlated with biosecurity score on dairy cattle farms. Previous studies on pig herds provided data on biosecurity practices only [10, 11] while some also addressed the question of factors influencing the implementation of biosecurity measures. Postma et al. [12] found that biosecurity status in pig farms in four European countries was significantly associated with the number of pathogens vaccinated against, with more weaned piglets per sow per year, and with the estimated frequency of treatment against certain clinical signs of disease. Sociotechnical factors such as "the female caretaker in the farrowing unit," "a farmer with fewer years of experience," "more educated personnel," "age of buildings," and "herd size" have been found to be associated with the biosecurity status in pig herds $[11,13]$.

To our knowledge, such factors have not yet been investigated in pig farming in Cameroon. Therefore, the objectives of this study were to describe the characteristic of pig farming, to determine the biosecurity score, and to investigate the socioeconomic and technical characteristics of farms and farmers affecting the implementation of biosecurity measures in the western highlands of Cameroon.

\section{Materials and Methods}

2.1. Study Area. The study was carried out from May to July 2017 on pig farms located in Menoua Division (Figure 1) in the
West Region of Cameroon. The area lies between longitude $9^{\circ} 49^{\prime}-10^{\circ} 20^{\prime}$ east of the Greenwich meridian and latitude $5^{\circ} 17^{\prime}-6^{\circ} 22^{\prime}$ north of the equator. The region is characterized by a typical climate with two main seasons, the dry season ranging from November to mid-March and the rainy season which prevails from mid-March to October. Temperature ranges between $15^{\circ}$ and $24^{\circ} \mathrm{C}$ [14]. Livestock species include pigs, small ruminants (sheep, goat), cattle, domestic cavies (Cavia porcellus), and poultry. The West Region is one of the highest pig production regions of the country, and one of the foci of ASF outbreak in the country [2, 4]. The last outbreak of ASF dates back to 2016, and the most recent report on pig population in the West Region gives an estimated pig population of 155,000 heads in 2016; these data were obtained from the regional authorities of the Ministry of Livestock, Fisheries and Animal Industry (MINEPIA) of the West Region.

2.2. Questionnaire Design. The questionnaire was divided into three sections. The first question set consisted of socioeconomic characteristic of farmers (age, sex, education, farming, and experience, among others). The second part was related to production characteristics such as farm size, breed, and production system. The third section was made up of questions dealing with biosecurity components including isolation, traffic control, and sanitation, as defined by FAO/OIE/ World Bank [15]. Before starting the field work, the questionnaire was pretested and the questions were adjusted accordingly. Pretesting of the questionnaire was carried out by the investigators among a small sample of pig farmers. Adjustments were made by replacing some words, deleting irrelevant questions, and reformulating and splitting some questions.

2.3. Selection of Farms. The areas to sample were chosen under the guidance of the veterinary health officials as the 
subdivisions where pig husbandry was known to take place. Given that previous reliable data on pig farmers were not available, all pig farms within the sample area were included in the study. In the absence of official registry of pig farms, farms were first located with the help of the local veterinary health officials. The next farms were located using the snow ball technique (the manager of the previously located farm helped to identify the next farm and so on until the whole area was covered). According to the regional authorities of the MINEPIA of the West Region, Menoua Division is one of the highest pig farming areas of the West Region. The questionnaire survey was carried out through a face-to-face interview between the researchers and the pig farm manager and through personal observations of the researchers. Only the pig farm manager was eligible for interview.

2.4. Biosecurity Scoring System. A technical scoring system was developed from the biosecurity indicators (measures), ranging from 0 to 1 . A biosecurity measure was coded as 1 if this measure is present (implemented), or 0 if the measure is absent (not implemented) $[9,16,17]$. To obtain the final score for each measure, all the values recorded on farms (either 0 or 1 per farm) were added up. The measures were grouped into sections, each section corresponding to a biosecurity component (isolation, traffic control, and sanitation). Since a component is made up of several measures, the scores of individual measures were added up to generate the mean score for the component, by dividing the total score by the total number of measures within a component. The maximum score for a given measure (biosecurity indicator) was 97 points matching the total number of farms under investigation while the maximum score for a given farm was 31 matching the total number of measures investigated.

2.5. Statistical Analysis. The farmer's related characteristics were examined using descriptive statistics (frequency and mean). The ANOVA test was used to test the effect of biosecurity component on biosecurity measures score. The test aimed at assessing whether the implementation level of biosecurity was the same among the three components of biosecurity (isolation, traffic control, and sanitation). The multivariate linear regression model was used to evaluate the relation between the biosecurity score of farms and the socioeconomic and technical characteristics (factors) of farmers and farms. To perform the analysis, qualitative variables were coded by creating dummy variables with two values, either 1 or 0 , while considering the reference level for the factor as the level with the lowest value. Collinearity was checked by looking at the values of the "Tolerance" and the Variance Inflation Factor (VIF) of variables; a "Tolerance" < 0.1 is indicative of redundancy of a variable, and a VIF greater than 10 indicates a collinearity problem. Data were analyzed using the SPSS statistical package (version 13.0, SPSS Inc., USA), and the significance level was fixed as $5 \%$.

\section{Results}

3.1. General Characteristics of Farmers and Farms. The general characteristics of pig farmers and farms are presented in Table 1. This table showed that most farmers are males (76.29\%), crop producers, on average $47.82 \pm 10.34$ years old (range: $32-67)$, married (65.96\%), have schooled up to secondary level $(53.61 \%)$, and have been trained in animal husbandry (70.10\%); animal husbandry referred to animal rearing in general, irrespective of the species. The highest proportion of farmers is Christian $(79.46 \%)$ and the lowest Muslim (0.86\%). The average number of years farmers had experience in rearing animals was $10.86 \pm 6.42$ years (range: $1-22)$. The most common husbandry system was extensive $(73.22 \%)$ while the mean herd size was $16.87 \pm 11.04$ pigs (range: $2-41$ ) and the mean farm age $8.18 \pm 5.56$ years (range: 2-22); farm age referred to years since start of the farm, not age of buildings.

3.2. Score of Biosecurity Indicators and Components. The score of indicators of biosecurity, as well as the mean score for each biosecurity component, is shown in Table 2. For indicators belonging to the isolation component of biosecurity, those with high score $(>50)$ included distance between two farms greater than $500 \mathrm{~m}$, quarantine of new animals, keeping animals of the same age in the same rooms, and absence of pigs at employees' home. The indicator with the poorest score was the use of herd specific clean coverall and boots by employees on farm (6 points over 97). The score for indicators pertaining to traffic control varied from 0 to 93 points for presence of entry restriction sign post and nonexchange of production materials (feeders, drinkers, shovel, wheelbarrow, and broom, among others) among farms, respectively. Measures with high score $(>50)$ also included assignment of each employee to a specific building, quarantine of unsold pigs returning from a market, and use of boars from own farm; quarantine period usually took a few days (2 days onwards) during which animals, kept in a separate stable, were observed for any change in behavior and any sign of disease. Indicators under sanitation had scores ranging from 0 to 90 . The score of half of the indicators was below 50. Of these measures, two had scores lower than 5, namely, presence of sanitary lock (score $=0 / 97)$ and disinfection of vehicles entering the farm (score $=4 / 97$ ). For the remaining half, two indicators had score greater than or equal to 90 , including the daily cleaning (floor, drinkers and feeders cleaned from dirt, and dung and feed waste each morning before feed supply) of the piggery and use of disinfectants. The ANOVA test of the effect of biosecurity component on the score of biosecurity indicators revealed that this effect was not significant ( $p=0.89$ ); indeed the mean scores of biosecurity components were not significantly different.

3.3. Factors Influencing the Use of Biosecurity Measures. The results of multivariate regression analysis of factors affecting the implementation of biosecurity measures are presented in Table 3. From this table, negative significant relationship was established between production systems and farm biosecurity score. The biosecurity score was 6.57 and 3.66 points lower for extensive and semi-intensive farms, respectively, than for intensive system. 
TABLE 1: General characteristics of pig farmers and farms in Menoua Division.

\begin{tabular}{|c|c|c|c|c|}
\hline \multirow{2}{*}{ Characteristics } & \multicolumn{3}{|c|}{ Subdivisions } & \multirow{2}{*}{ Total $(N=97)$} \\
\hline & Dschang $(n=41)$ & Fokoué $(n=32)$ & Penka Michel $(n=24)$ & \\
\hline \multicolumn{5}{|l|}{ Sex of farmer } \\
\hline Male & 24,36 & 78,10 & 75,00 & 76,29 \\
\hline Female & 75,61 & 21,88 & 25,00 & 23,71 \\
\hline Farmer age $($ mean $\pm S D)$ & $47.04 \pm 10.18$ & $49.34 \pm 10.31$ & $47.12 \pm 10.85$ & $47.82 \pm 10.34$ \\
\hline \multicolumn{5}{|l|}{ Education level } \\
\hline Never been to school & 12.20 & 12.50 & 25.00 & 15.46 \\
\hline Primary & 17.07 & 12.50 & 4.17 & 12.37 \\
\hline Secondary & 53.66 & 56.25 & 50.00 & 53.61 \\
\hline Higher education & 17.07 & 18.75 & 20.89 & 18.56 \\
\hline \multicolumn{5}{|l|}{ Training in animal husbandry } \\
\hline Yes & 24.39 & 28.12 & 25.00 & 29.89 \\
\hline No & 75.61 & 71.87 & 75.00 & 70.10 \\
\hline \multicolumn{5}{|l|}{ Main activity } \\
\hline Crop farming & 34.15 & 50.00 & 33.33 & 39.18 \\
\hline Animal husbandry & 29.27 & 15.63 & 29.17 & 24.74 \\
\hline Trade & 21.95 & 15.63 & 20.83 & 19.59 \\
\hline Civil servant & 9.76 & 9.38 & 8.33 & 9.28 \\
\hline Retired & 4.88 & 9.38 & 8.33 & 7.22 \\
\hline \multicolumn{5}{|l|}{ Religion } \\
\hline Christian & 82.05 & 80.42 & 75.89 & 79.46 \\
\hline Muslim & 0.00 & 0.00 & 2.58 & 0.86 \\
\hline Animist & 17.95 & 19.58 & 21.53 & 19.68 \\
\hline \multicolumn{5}{|l|}{ Matrimonial status } \\
\hline Married & 63.41 & 65.63 & 45.83 & 65.96 \\
\hline Bachelor & 29.26 & 25.00 & 37.51 & 23.28 \\
\hline Widow(er) & 7.32 & 9.37 & 16.66 & 7.76 \\
\hline Experience in animal husbandry (years) (mean $\pm S D)$ & $10.75 \pm 6.16$ & $11.84 \pm 6.81$ & $9.75 \pm 6.39$ & $10.86 \pm 6.42$ \\
\hline \multicolumn{5}{|l|}{ Husbandry system ${ }^{\dagger}$} \\
\hline Extensive & 69.25 & 72.64 & 77.78 & 73.22 \\
\hline Semi-intensive & 24.89 & 22.55 & 19.89 & 22.45 \\
\hline Intensive & 5.86 & 4.80 & 2.33 & 4.33 \\
\hline Herd size $($ mean $\pm S D)$ & $17.14 \pm 11.62$ & $21 \pm 9.89$ & $15.21 \pm 10.67$ & $16.87 \pm 11.04$ \\
\hline Farm age $($ mean $\pm S D)$ & $8.15 \pm 5.39$ & $8.84 \pm 6.07$ & $7.37 \pm 5.25$ & $8.18 \pm 5.56$ \\
\hline
\end{tabular}

\section{Discussion}

This study is the first one describing the characteristics of pig farmers and pig farms, as well as the implementation of certain biosecurity measures on pig farms and factors influencing the implementation of biosecurity measures on the farm within the study area. In order to collect reliable data, face-to-face interviews and field observations were used to complete the questionnaire rather than using mailed questionnaires.

The results of this work indicated that the main actors in pig farming are men above forty years old, which disagree with the findings on Swedish pig farms [11] where the proportion between men and women pig farms managers is balanced. Concerning the age of pig farm manager, our findings agree with those on Swedish pig farms [11] where the mean age should be around 40 , based on the median of 23 years (range: 5-41 years) of experience in pig farming. The old age of persons in charge of pigs in Cameroon might be related to the high schooling rate of the population in the study area where young people mostly spend their time at school and thus cannot properly take care of animals. In the country also, animal husbandry is mostly carried out by men rather than women, who are mostly involved in crop 


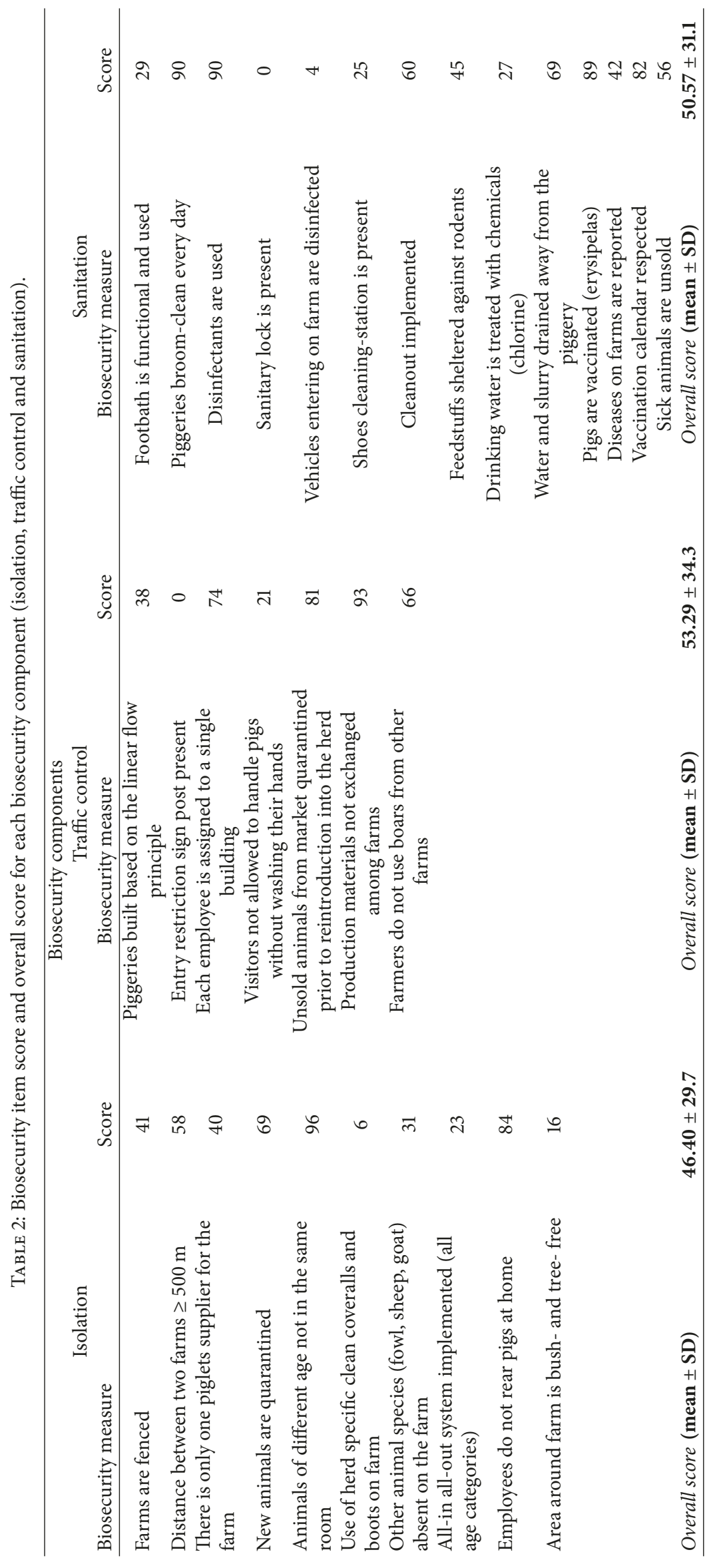


TABLE 3: Regression result of socioeconomic characteristics of pig farmers and technical characteristic of farms influencing the biosecurity score of farms.

\begin{tabular}{|c|c|c|}
\hline Characteristics & Regression coefficient & $p$-value \\
\hline \multicolumn{3}{|c|}{ Socioeconomic characteristics of farmers } \\
\hline Age (years) & -0.004 & 0.953 \\
\hline \multicolumn{3}{|l|}{ Gender } \\
\hline Male & 0.552 & 0.658 \\
\hline Female & Ref. & \\
\hline \multicolumn{3}{|l|}{ Education } \\
\hline Higher education & 1.489 & 0.309 \\
\hline Secondary education & -0.224 & 0.858 \\
\hline Primary education & 0.847 & 0.571 \\
\hline Never been to school & Ref. & \\
\hline \multicolumn{3}{|c|}{ Training in animal husbandry } \\
\hline Yes answer & 0.387 & 0.985 \\
\hline No answer & Ref. & \\
\hline \multicolumn{3}{|l|}{ Main activity } \\
\hline Crop producer or breeder & -3.040 & 0.103 \\
\hline Trader or civil servant & -2.108 & 0.315 \\
\hline Retired & Ref. & \\
\hline \multicolumn{3}{|l|}{ Member of a cooperative } \\
\hline Yes & 0.611 & 0.591 \\
\hline No & Ref. & \\
\hline \multicolumn{3}{|l|}{ Technical characteristic of farms } \\
\hline Farm age (years) & 0.121 & 0.270 \\
\hline Herd size & 0.017 & 0.596 \\
\hline \multicolumn{3}{|l|}{ Husbandry system ${ }^{\dagger}$} \\
\hline Extensive system & $-6.569^{*}$ & 0.000 \\
\hline Semi-extensive & $-3.658^{*}$ & 0.005 \\
\hline Intensive & Ref. & \\
\hline
\end{tabular}

${ }^{*} p<0.05 ;{ }^{\dagger}$ extensive system $=$ animals of relatively small number are permanently penned and feed on agriculture by-products and kitchen wastes; semiintensive system = cross-bred animals are permanently penned in piggeries with a roughcast floor and feed on kitchen waste, agricultural by-products and often industrial feed; intensive system = animals are improved breeds, indoors, in high number; the piggery is a modern building; feedstuff is exclusively industrial; management system is modern.

production. Men's deep involvement in animal husbandry rather than in crop farming is cultural and is inherited from tradition. The majority of people responsible for pigs had secondary school education level, with 10 years of experience in animal husbandry, but were not formally trained in animal husbandry. In comparison with the Swedish pig farmers [11], Cameroon pig farmers also had the relevant years of experience and the education level but not the educational background (training in animal husbandry) required in pig husbandry. That most pig farmers in Cameroon were not trained in animal production is a flaw for pig industry in the country. Animal husbandry was not the main activity of pig farmers within the study area but crop production. Other main occupations also included trade or office work (civil servants); a minority were retired. This picture gives the impression that pig farming alone does not allow the farmers to make a living within the study area. The reason for this may be related to recurrent epidemics of ASF that has been decimating the herds in different localities of the country. Concerning farmers' religion, the lowest proportion of farmers were Muslims probably due to religious restrictions. Though Muslims are known to avoid pork and are often overlooked when addressing questions dealing with pig industry, this study showed that they should be reckoned with not as consumers, but as producers. The mean herd size was $16.87 \pm 11.04$, with a minimum of 2 and a maximum of 41 . Costard et al. [18] reported a minimum herd size of 2 and a maximum of 98 in Madagascar. In spite of the maximum herd size in Madagascar greater than the maximum size in Cameroon, the median size in Madagascar varying from 3 to 7 suggests that the herd size and the production systems in both countries are the same. This may be partly due to the common disease challenges faced by pig industry in both countries, especially the regular outbreaks of contagious diseases, such as ASF [2, 19-21]. In fact, the high mortality rate of these diseases (close to $100 \%$ for ASF) in affected 
farms causes farm owners either to remain only with the few survivors, to restock the farms with few animals, or to take less risk in investing for a larger farm.

The biosecurity scoring system adopted in this work was a linear scoring system (each measure is equally scored) $[16,17,22]$ rather than a risk based weighted scoring system $[13,23]$. Authors supporting the weighted scoring system consider that each pathway of disease transmission has a different or peculiar efficiency $[13,23]$; their standpoint is supported by some examples such as the fact that direct contact between animals (contact between healthy animals and diseased animals newly purchased) poses a higher risk whereas indirect contacts (transmission of pathogens through rodents or tools sharing between farms) are less efficient in the transmission of pathogens. Though they are right, the linear scoring system was preferred in this study for simplicity reasons. The linear system considers each measure of equal weight, whether it poses higher or lower risk to the farm. The choice was also guided by the desire to make the scoring system comprehensive for the farmers and stakeholders of pig industry.

This study revealed that measures belonging to the three components of biosecurity were equally implemented, since the mean scores of the investigated components were not significantly different. However, within each component, some measures recorded higher scores while others were not implemented at all. For isolation component, measures with the highest score $(>80)$ included "employees do not rear pigs at home" and "animals of different age not in the same room". An explanation for these high scores could be that most farms have family members as workers, and in order to reduce competition for food, farmers are aware of the need to keep pigs of the same age together in the same room, rather than mixing large and small animals in the same area. The measure with the lowest score was "use of herd specific clean coveralls and boots on farm"; the lowest score is in part due to the fact that most workers do not possess dedicated clothing for farms. Effective use of coveralls and boots was observed only in intensive farms which are less represented in the study area. Thus, the low score is also likely related to the low number of intensive farms. Differences in management and biosecurity practices between smallholder and commercial (intensive) pig farms have been described also in the Philippines [24].

For measures under traffic control component, "unsold animals from market quarantined prior to reintroduction into the herd" and "production materials not exchanged among farms" were the measures with the highest score (>80) while the measure with the smallest score was "entry restriction sign post present". Quarantine of animals from markets is a very useful biosecurity measure given that markets are public places where contact among animals from various origins and with different health status is optimal. In line with the high score concerning quarantine, it is advisable for farmers to avoid contact between own animals and other animals at the market and to disinfect any vehicle coming from the market, used to carry animals before it enters the farm. Similarly, it is very helpful not to exchange production materials (drinkers, feeders, buckets, and other tools) between farms. The high quarantine score in this study is in accordance with recommendations for biosecurity considerations on pig farms [25]. The high score observed is probably related to the awareness of farmers of the dangers associated with overlooking this measure, following the ASF outbreak and the subsequent warning and sensitization through the media (radio, televisions, and newspapers) about the main ASF transmission routes. The adoption of this measure should be sustained and encouraged not only because of ASF but also because of the zoonotic pandemic $\mathrm{H} 1 \mathrm{N1}$ virus ( $\mathrm{pdm} / 09$ ), the etiologic agent of influenza A reported in pigs in Cameroon [26]. The fact that none of the farmers used a physical indication such as a sign post to deter people from entering the farm or from allowing pet animals to enter the farm is due to the lack of awareness of the importance of this measure. Such a practice is contrary to practices adopted by many European pig farmers whose most important biosecurity measures are those that aim at minimizing the risk of disease introduction by visits and vehicles [12, 27]. Visitors with their vehicles may unknowingly enter the farm with their pet animal such as dog or cat and reach the animal living areas where they as well as the pet animal may transmit a disease to a flock either by direct contact or by shedding the pathogen through the excreta (feces, urine, or saliva).

The measures evaluated under the sanitation biosecurity component with high score (>80) included "piggeries clean every day", "disinfectants are used", "pigs are vaccinated", and "vaccination calendar respected" while that recording the lowest score was "sanitary lock is present". Vaccination is done twice a year against erysipelas which has become endemic in the region; the vaccine used is given, according to the manufacturer's instructions, after a six-month period to growers and adults. The high score of these hygienic measures might be justified by the fact that these are basic measures easy to implement at very cheap cost. It is important to mention that, in Cameroon, vaccination of pigs and large ruminants against many contagious diseases is subsidized by the government. Also, the fear for outbreak of contagious disease such as ASF and erysipelas has pushed farmers to be receptive to advice and recommendations from the veterinary health officers and to adopt those that are cheap and easy to apply. Indeed, Fraser et al. [28] found that there is a converse relationship between the willingness of farmers to adopt a biosecurity measure and its implementing cost. However, results from recent studies showed that implementation of biosecurity measures leads to more financial profit, reduced usage of antimicrobials, and improved technical performance in pig production [29-31]. No farm was found to possess a sanitation lock in this study, though the sanitation lock is essential for keeping visitors and workers clean on the farm [25]. The null score probably has to do with financial considerations but lack of sanitary lock is contrary to recommendations for good biosecurity practices on pig farms [25].

Considering all the biosecurity measures, the score of more than half of them is below the average score of a given measure (49 points), indicating that the biosecurity level of the investigated farms is low. It is therefore important for farmers to seriously reconsider the biosecurity practices on their farms by implementing the required biosecurity 
measures on their farms. Previous studies evaluating the impact of the implementation of biosecurity measures in pig herds in Europe only showed advantageous results, notably decreased usage of antimicrobials, a drop in disease outbreaks, an increased technical performance, and more profit [29-31]. Policymakers should encourage farmers to implement biosecurity measures and even organize training and sensitization workshops on biosecurity in pig production.

The farm biosecurity score was significantly related to the production system, with the score lower in extensive and semi-intensive system compared with the intensive system. Our results are in tandem with previous observations [15, 32]. Some measures (avoiding introduction of pigs from outside, neighboring farm, markets or villages in the herd, ensuring long distances between farms, or shower with change of clothing and footwear, among others) implemented in the intensive system are not easily applicable in the extensive system. Thus, the relationship between biosecurity score and production system was expected given that implementation of standard biosecurity measures is limited in extensive and semi-intensive systems. Herd size is often correlated with the biosecurity score $[9,13]$, but in this study, this was not the case likely due to the relatively small herd sizes in general.

\section{Conclusions}

Pig farming in the western highlands of Cameroon is not the main farmers' activity, probably resulting from regular outbreaks of contagious diseases. Most farms are extensive with relatively small herd sizes and labor coming from family members. Biosecurity measures with high scores are basic (hygienic measures) or those cheap to implement. In general, the biosecurity level of the investigated farms was poor with more than half of the measures recording the score below the average score for a given measure. A significant relationship was found between farm biosecurity score and farm production system. With the results obtained in this study, stakeholders of pig industry in Cameroon and other countries with similar pig farming system can improve the general biosecurity status in pig production, which in turn will probably help in limiting the outbreak of diseases, improving the technical performance and economic gain. Policymakers should encourage farmers to implement biosecurity measures and even organize training and sensitization workshops on biosecurity in pig production in the country.

\section{Data Availability}

The data are included in the tables within the manuscript.

\section{Conflicts of Interest}

The authors declare that they have no conflicts of interest.

\section{Acknowledgments}

The authors would like to express their gratefulness to farmers for their warm welcome during their visit on their farms and for agreeing to answer their questions. They also thank the government veterinary and public health officers for their assistance in locating the pig farms.

\section{References}

[1] FAO Statistical Pocketbook 2015, Food and Agriculture Organization of the United Nations, Rome, 2015.

[2] MINEPIA (Cameroon, Ministry of Livestock, Fisheries, and Animal Industries), Schéma directeur pour le développement des filières de l'élevage au Cameroun, volume 2: cartographie des filières, Yaoundé, Cameroun, 2009.

[3] MINEPIA (Ministère de l'Élevage, des Pêches et des Industries Animales, Cameroun), Situation de la production du soussecteur élevage, pêches et industries animales en 2013, Yaoundé, Cameroun, 2014.

[4] MINEPIA/FAO, (Cameroon, Ministry of Livestock, Fisheries, and Animal Industries/ Food and Agriculture Organization of the United Nations), Schéma directeur pour le développement des filières de l'élevage au Cameroun, volume 1: Document principal, Yaoundé, Cameroun, 2009.

[5] NIS (National Institute of Statistics, Cameroon), Annuaire statistique du Cameroun: Recueil des séries d'informations statistiques sur les activités économiques, sociales, politiques et culturelles $d u$ pays jusquen 2013, 2013, http://www.statistics-cameroon.org/.

[6] G. J. Gunn, C. Heffernan, M. Hall, A. McLeod, and M. Hovi, "Measuring and comparing constraints to improved biosecurity amongst GB farmers, veterinarians and the auxiliary industries," Preventive Veterinary Medicine, vol. 84, no. 3-4, pp. 310323, 2008.

[7] F. O. Fasina, D. D. Lazarus, B. T. Spencer, A. A. Makinde, and A. D. S. Bastos, "Cost Implications of African Swine Fever in Smallholder Farrow-to-Finish Units: Economic Benefits of Disease Prevention Through Biosecurity," Transboundary and Emerging Diseases, vol. 59, no. 3, pp. 244-255, 2012.

[8] C. O. Ajewole and A. A. Akinwumi, "Awareness and Practice of Biosecurity Measures in Small Scale Poultry Production in Ekiti State, Nigeria," Journal of Agricultural and Veterinary Science, vol. 7, no. 11, pp. 24-29, 2014.

[9] M. F. Can and N. Altuğ, "Socioeconomic implications of biosecurity practices in small-scale dairy farms," Veterinary Quarterly, vol. 34, no. 2, pp. 67-73, 2014.

[10] S. Ribbens, J. Dewulf, F. Koenen et al., "A survey on biosecurity and management practices in Belgian pig herds," Preventive Veterinary Medicine, vol. 83, no. 3-4, pp. 228-241, 2008.

[11] A. Backhans, M. Sjölund, A. Lindberg, and U. Emanuelson, "Biosecurity level and health management practices in 60 swedish farrow-to-finish herds," Acta Veterinaria Scandinavica, vol. 57, no. 1, article no. 14, 2015.

[12] M. Postma, A. Backhans, L. Collineau et al., "The biosecurity status and its associations with production and management characteristics in farrow-to-finish pig herds," Animal, vol. 10, no. 3, pp. 478-489, 2015.

[13] M. Laanen, D. Persoons, S. Ribbens et al., "Relationship between biosecurity and production/antimicrobial treatment characteristics in pig herds," The Veterinary Journal, vol. 198, no. 2, pp. 508-512, 2013. 
[14] IRAD (Institut de Recherche Agricole pour le Développement, Cameroun), Rapport annuel des activités, 2012.

[15] "FAO/WHO/World Bank (Food and Agriculture Organization of the United Nations/World Organisation for Animal Health/World Bank), 2010," Good practices for biosecurity in the pig sector - Issues and options in developing and transition countries. FAO Animal Production and Health Paper No. 169. Rome.

[16] S. Sarrazin, A. B. Cay, J. Laureyns, and J. Dewulf, "A survey on biosecurity and management practices in selected Belgian cattle farms," Preventive Veterinary Medicine, vol. 117, no. 1, pp. 129139, 2014.

[17] S. Van Steenwinkel, S. Ribbens, E. Ducheyne, E. Goossens, and J. Dewulf, "Assessing biosecurity practices, movements and densities of poultry sites across Belgium, resulting in different farm risk-groups for infectious disease introduction and spread," Preventive Veterinary Medicine, vol. 98, no. 4, pp. 259-270, 2011.

[18] S. Costard, V. Porphyre, S. Messad et al., "Multivariate analysis of management and biosecurity practices in smallholder pig farms in Madagascar," Preventive Veterinary Medicine, vol. 92, no. 3, pp. 199-209, 2009.

[19] T. Randriamparany, A. Grenier, I. Tourette, C. Y. Maharavo Rahantamalala, D. Rousset, and R. Lancelot, "Situation épidémiologique de la peste porcine africaine dans la région du lac Alaotra (Madagascar) et conséquences possibles pour lorganisation de la lutte et de la surveillance," Revue d'élevage et de médecine vétérinaire des pays tropicaux, vol. 58, no. 1-2, p. $15,2005$.

[20] M. F. Nana-Nukechap and E. P. J. Gibbs, "Socioeconomic effects of African swine fever in Cameroon," Tropical Animal Health and Production, vol. 17, no. 4, pp. 183-184, 1985.

[21] N. F. Ekue, P. J. Wilkinson, and R. C. Wardley, "Infection of pigs with the Cameroon isolate (Cam/82) of African swine fever virus," Journal of Comparative Pathology, vol. 100, no. 2, pp. 145154, 1989.

[22] C. V. Maduka, I. O. Igbokwe, and N. N. Atsanda, "Appraisal of Chicken Production with Associated Biosecurity Practices in Commercial Poultry Farms Located in Jos, Nigeria," Scientifica, vol. 2016, Article ID 1914692, 2016.

[23] M. Laanen, J. Beek, S. Ribbens, F. Vangroenweghe, D. Maes, and J. Dewulf, "Biosecurity on pig herds: Development of an on-line scoring system and the results of the first 99 participating herds," Vlaams Diergeneeskundig Tijdschrift, vol. 79, no. 4, pp. 302-306, 2010.

[24] J. I. Alawneh, T. S. Barnes, C. Parke et al., "Description of the pig production systems, biosecurity practices and herd health providers in two provinces with high swine density in the Philippines," Preventive Veterinary Medicine, vol. 114, no. 2, pp. 73-87, 2014.

[25] G. Pritchard, I. Dennis, and J. Waddilove, "Biosecurity: Reducing disease risks to pig breeding herds," In Practice, vol. 27, no. 5, pp. 230-237, 2005.

[26] C. J. Snoeck, O. J. Abiola, A. Sausy et al., "Serological evidence of pandemic (H1N1) 2009 virus in pigs, West and Central Africa," Veterinary Microbiology, vol. 176, no. 1-2, pp. 165-171, 2015.

[27] M. Simon-Grifé, G. E. Martín-Valls, M. J. Vilar-Ares et al., "Biosecurity practices in Spanish pig herds: Perceptions of farmers and veterinarians of the most important biosecurity measures," Preventive Veterinary Medicine, vol. 110, no. 2, pp. 223-231, 2013.
[28] R. W. Fraser, N. T. Williams, L. F. Powell, and A. J. C. Cook, "Reducing Campylobacter and Salmonella infection: Two studies of the economic cost and attitude to adoption of on-farm biosecurity measures," Zoonoses and Public Health, vol. 57, no. 7-8, pp. e109-e115, 2010.

[29] M. Postma, W. Vanderhaeghen, S. Sarrazin, D. Maes, and J. Dewulf, "Reducing Antimicrobial Usage in Pig Production without Jeopardizing Production Parameters," Zoonoses and Public Health, vol. 64, no. 1, pp. 63-74, 2017.

[30] L. Collineau, C. Rojo-Gimeno, A. Léger et al., "Herd-specific interventions to reduce antimicrobial usage in pig production without jeopardising technical and economic performance," Preventive Veterinary Medicine, vol. 144, pp. 167-178, 2017.

[31] C. Rojo-Gimeno, M. Postma, J. Dewulf, H. Hogeveen, L. Lauwers, and E. Wauters, "Farm-economic analysis of reducing antimicrobial use whilst adopting improved management strategies on farrow-to-finish pig farms," Preventive Veterinary Medicine, vol. 129, pp. 74-87, 2016.

[32] E. F. Gueye, Biosécurité pour les fermes avicoles (Secteurs3 \& 4) et les marchés de volailles vivantes, FAO, Rome, 2008. 

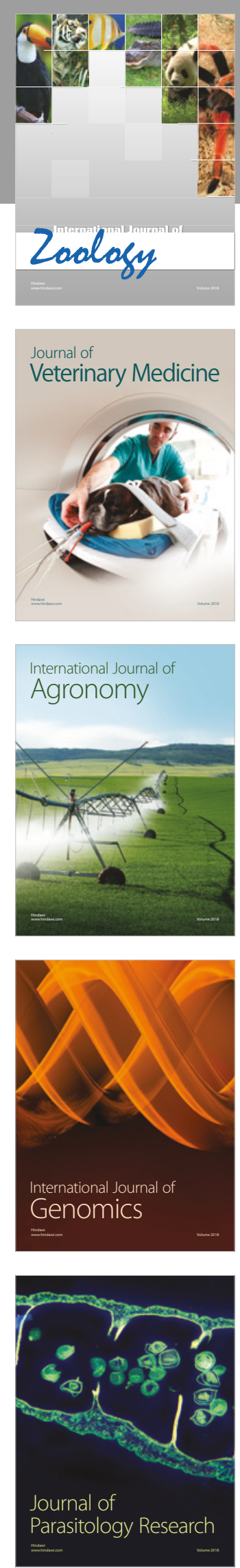

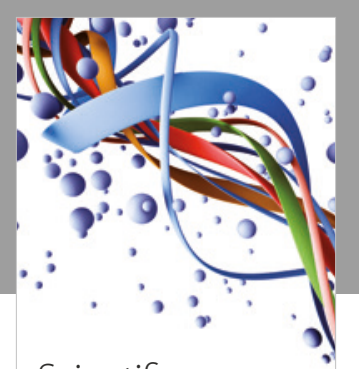

Case Reports in Veterinary Medicine Scientifica
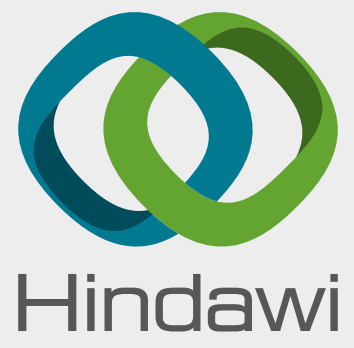

Submit your manuscripts at

www.hindawi.com
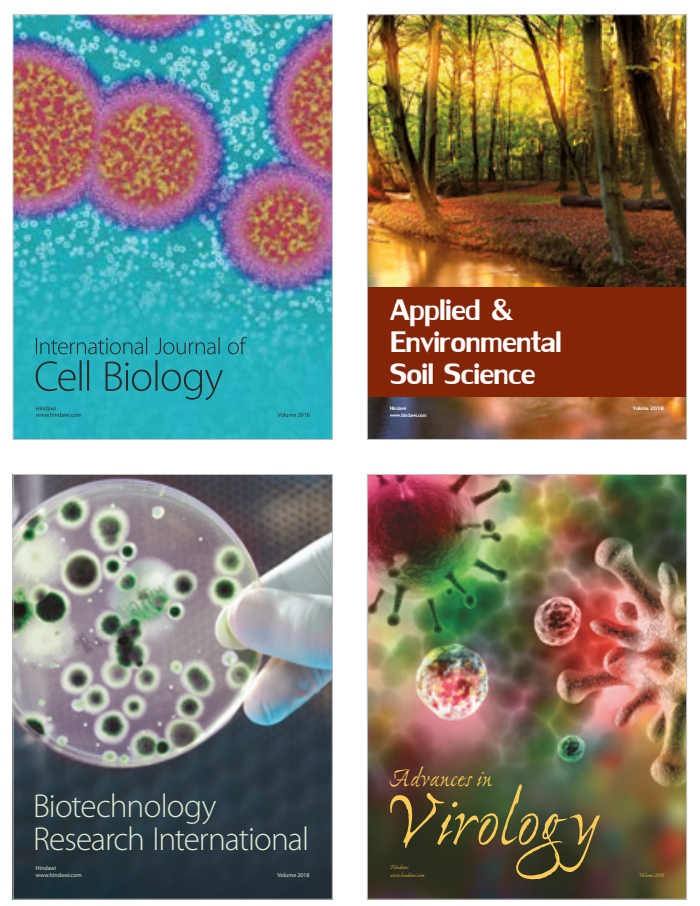

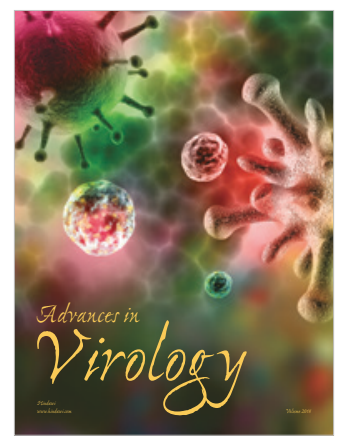

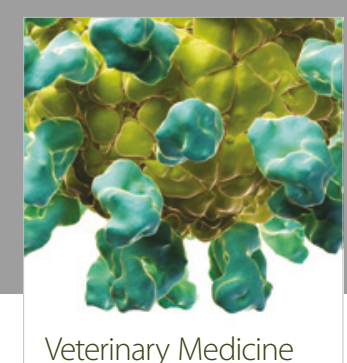
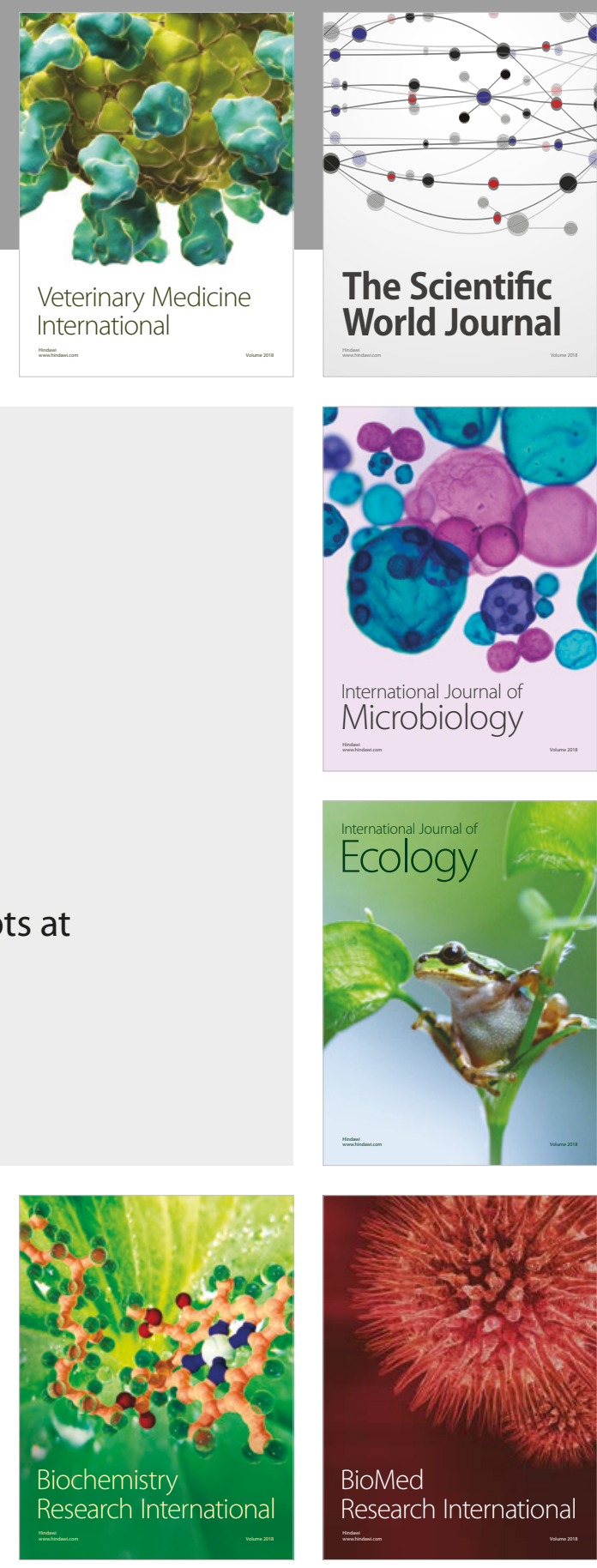

The Scientific World Journal

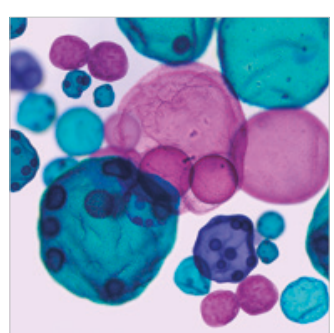

International Journal of Microbiology
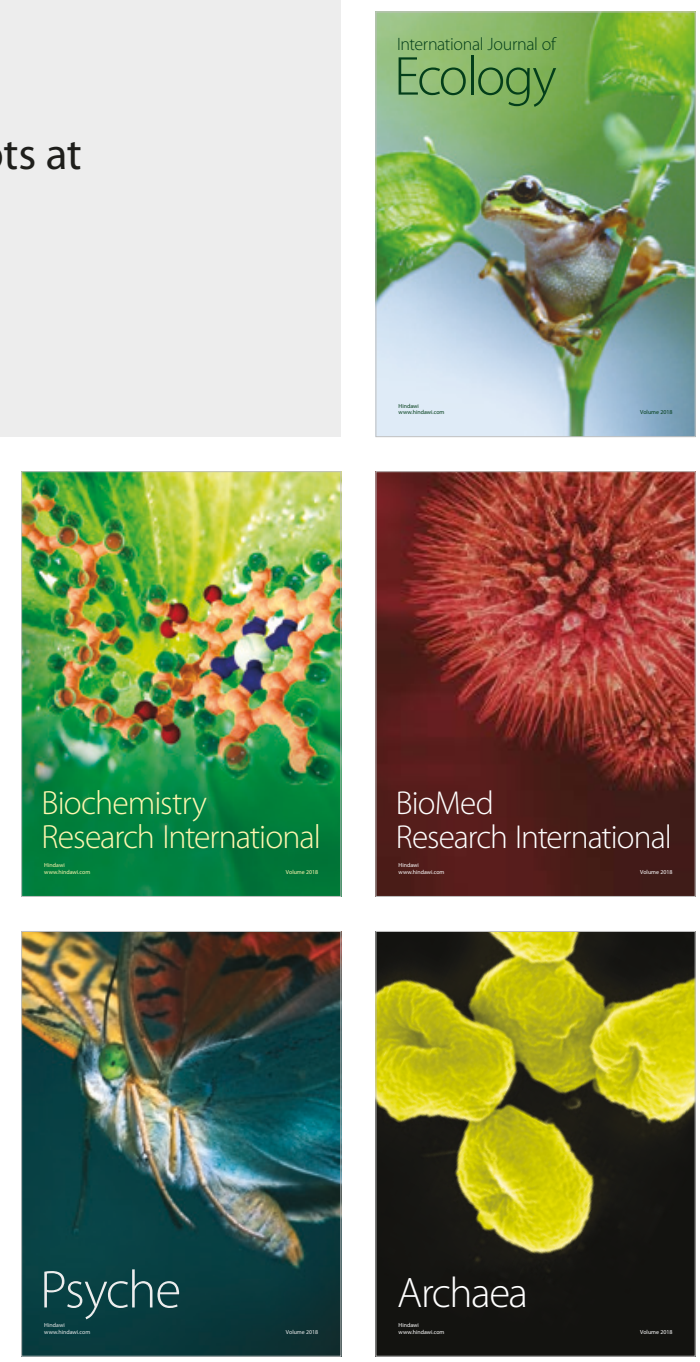